\section{Ser/estar professor: desafios da prática docente da licenciatura em Letras}

\author{
To be a teacher: challenges \\ of the teaching practice of \\ licentiate in Letters
}

Maria Edilene de Paula KOBOLT (Unilasalle) mariaedilenekobolt@gmail.com

Ane Patrícia Viana José de MIRA (Unilasalle) ane.mira23@gmail.com

Recebido em: 31 de maio de 2018. Aceito em: 22 de set. de 2018.

\title{
00000000000
}

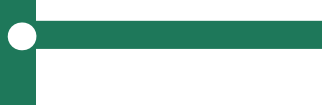

KOBOLT, Maria Edilene de Paula; MIRA, Ane Patrícia Viana José de. Ser/ estar professor: desafios da prática docente da licenciatura em Letras. Entrepalavras, Fortaleza, v. 8, n. 3, p. 230-243, out-dez/2018.

Resumo: O presente trabalho tem por tema a formação dos professores nos cursos de licenciatura em Letras. O objetivo é analisar a formação dos professores nos cursos de licenciatura em Letras pela perspectiva do professorreflexivo e do humanismo freiriano. Trata-se, portanto, de uma pesquisa de abordagem qualitativa, com coleta de dados em relatos de experiência de alunos da graduação do curso de Letras de uma universidade privada do sul do Brasil. A análise do conteúdo foi realizada seguindo a técnica de Bardin. Os resultados apontaram para duas categorias básicas de formação de professores no curso de Letras investigado: o aluno-professor que reafirma seu perfil docente com a prática do estágio e o aluno-professor que forma sua identidade docente com a prática do estágio. Além disso, é mister observar a necessidade de todos os estudantes de desenvolverem a consciência do professor reflexivo desde o início da graduação, estendendo-se por toda a trajetória docente dos profissionais, calcados em uma visão humanista e integral da pessoa humana.

Palavras-chave: Formação docente. Licenciatura em Letras. Professor reflexivo. 
Abstract: The present work has as its theme the training of teachers in undergraduate courses in Letters. The objective is to analyze the training of teachers in undergraduate courses in Letters from the perspective of teacher-reflective and Freirean humanism. It is, therefore, a qualitative research, with data collection in reports of experience of undergraduate students of the course of Letters of a private university in the south of Brazil. Content analysis was performed using the Bardin technique. The results pointed to two basic categories of teacher training in the literature course investigated: the studentteacher who reaffirms his teaching profile with the practice of the internship and the student-teacher who forms his / her teaching identity with the practice of the internship. In addition, it is necessary to observe the need of all students to develop the consciousness of the reflective teacher from the beginning of graduation, extending throughout the teaching career of professionals, based on a humanistic and integral vision of the human person.

Keywords: Teacher training. Licentiate in Letters. Reflective teacher.

\section{Introdução}

Não é de hoje que a busca pelos cursos de licenciatura no Brasil é baixa. O Censo da Educação Superior (BRASIL/MEC/INEP, 2016), apontou que somente $18,9 \%$ das matrículas no ensino superior são em cursos de licenciatura, em contrapartida dos $69 \%$ em cursos de bacharelado. Embora o relatório mostre um aumento de 3,3\% no crescimento das matrículas em cursos de licenciatura do ano de 2015 para o de 2016, a procura ainda é muito baixa se pensarmos que esses profissionais são os formadores de todas as crianças e jovens em nosso país. Inúmeros fatores são apontados como motivo para esses números: baixos salários, desvalorização da profissão perante a sociedade, desmonte do sistema educacional pelos governos, precariedade de condições de exercer a profissão, falta de recursos, entre outros. Saviani (2009, p. 153) afirma que "Tais condições dificultam uma boa formação, pois operam como fator de desestímulo à procura pelos cursos de formação docente e à dedicação aos estudos".

Outro dado interessante que surgiu no censo de 2016 (BRASIL/ MEC/INEP, 2016), é que dos 18,9\% de matrículas, 61,9\% são efetivadas nas instituições privadas no Brasil, contra 38,1\% em instituições públicas. Além disso, $71,1 \%$ dos estudantes são mulheres e somente $28,9 \%$ são homens. Assim, podemos observar um público majoritariamente feminino e com condições de pagar por seus estudos ou que são beneficiados por programas como o ProUni e financiamentos como o do Fies. São estudantes que normalmente trabalham no turno inverso ao de seus estudos na graduação e por isso não despendem de tempo exclusivo para sua formação. Esses perfis não podem ser deixados de lado quando se analisa a formação desses profissionais em relação ao tempo de contato com a sala de aula, seu preparo para o momento dos estágios, o desenvolvimento de sua consciência crítica em relação ao seu próprio estar ou ser professor. 
v. 8 (3)

$230-249$

out-dez

2018

Com essa problemática em foco, o presente estudo pretende analisar a formação do professor desde o início da graduação até sua inserção no estágio docente obrigatório. Para tanto, definimos o escopo da pesquisa ouvindo alunos da licenciatura de Letras, com habilitação em português e espanhol, presencial, em uma universidade do Sul do país. Ouvimos três alunos que contribuíram de forma voluntária com seus relatos. A escolha pelos sujeitos ouvidos foi de forma aleatória para amostragem do curso.

Com os dados coletados desses relatos, analisamos a constituição do professor-reflexivo a partir de autores como Pimenta (2012) e Freire (1996 e 2017). A análise foi realizada seguindo a técnica de Bardin (2016), segundo a qual observamos duas categorias de estudantes de Letras: o aluno-professor que reafirma seu perfil docente com a prática do estágio e o aluno-professor que forma sua identidade docente com a prática do estágio.

Importante reportarmos que, durante nossa busca por artigos no portal de periódicos da Capes, utilizando os descritores "estágio docente" e "prática docente", entre os anos de 2006 e 2017 somente 35 trabalhos foram encontrados. Destes, 8 artigos tratavam mais especificamente dos estudantes de graduação e nenhum tratava especificamente do aluno do curso de Licenciatura em Letras, pelo que consideramos essa investigação bastante relevante e oportuna. Pois, dado o momento de transição que vive nosso país em relação à educação, que pese a implementação da Base Nacional Comum Curricular (BRASIL, 2017), entre outras, analisar e refletir sobre a constituição do profissional docente para a educação básica é de suma importância. Por isso, articulamos nosso texto de modo a discorrer sobre o aporte teórico a respeito do professor-reflexivo, a interface com os relatos obtidos e, após, há a análise e discussão dos resultados, seguidas das considerações finais.

\section{Formação do professor-reflexivo}

Iniciamos nossa reflexão e análise com uma máxima ouvida há algum tempo atrás, oriunda do senso comum: "Professor não é valorizado porque é uma das profissões mais fáceis de seguir. Você estuda e passa no quadro a matéria. Além disso, tem mais férias que qualquer outro profissional". Partindo desta declaração, remontamonos em um mar de argumentos a favor da classe do professorado. Entretanto, vamos nos deter no início da construção desta profissão: o estudo, a graduação e, finalmente, a prática de ensino. 
A maioria dos estudantes de licenciatura em Letras inicia seus estudos com um ideal traçado: lutar pela educação, ensinar português, espanhol ou outro idioma aos alunos com muitos recursos, preparar suas aulas, projetos e aplicá-los. Porém, quando alguns desses graduandos, geralmente a maioria, têm seu primeiro contato com a sala de aula, depara-se com a frustação e o pensamento de que não era exatamente aquela realidade que esperava, ou seja, criaram-se expectativas acadêmicas, profissionais e pessoais que não foram correspondidas.

É necessário, nesse momento da atuação docente, que o futuro profissional permaneça em processo de reflexão. Ou seja, saiba que "A superação e não a ruptura se dá na medida em que a curiosidade ingênua, sem deixar de ser curiosidade, se criticiza." (FREIRE, 1996, p. 31). Sendo assim, é no cotidiano da prática docente que o estudante de licenciatura encontra seu lugar enquanto educador, enquanto aquele que supera as dificuldades e não se esmorece diante delas.

Neste contexto, podemos retomar o conceito de professorreflexivo estudado por alguns autores como Weber (2004) e Pimenta (2010) e buscar na vertente freiriana os saberes necessários à prática docente (FREIRE, 1996). Porque, no processo de construção docente seja início, meio e fim de uma graduação ou até mesmo na formação continuada - o conceito de professor-reflexivo precisa fazer parte contínua do ser professor. A reflexão calcada em fundamentação profunda sobre o fazer docente permite que o profissional olhe para si como um ser que reconheça suas fragilidades e que possa melhorar a cada momento sua prática pedagógica. Do mesmo modo, afirmou Freire (2017, p. 52-53): "O processo de consciência é um processo lento, mas que em última instância adquire sua firmeza no processo da própria realidade".

O norte-americano Schön (1995) imprimiu o conceito de professorreflexivo a partir de estudos realizados nos cursos de formação de professores. O autor tem como base a epistemologia pragmática para pensar na valorização de uma prática reflexiva na formação de professores, desenvolvendo neles a capacidade de responder a situações não previstas em determinados contextos (PIMENTA, 2010). Conforme Freire (2017), o educador ou professor-reflexivo é aquele capaz de fazer de sua prática uma forma de superar o status quo tecnicista da produção do conhecimento junto aos alunos.

Embrutecer a força de trabalho submetida a procedimentos rotineiros faz parte da natureza do modo de produção capitalista. O que se dá na produção do conhecimento na escola é, em grande parte, mesmo que possamos fazer o contrário, a reprodução desse mecanismo. (FREIRE, 2017, p. 78). 
v. 8 (3)

$230-249$

out-dez

2018

Portanto, de acordo com Schön (1995), entender de forma racional o que se faz oportuniza ao estudante a prática no sentido de que se faz e se aprende, ou seja, a prática será efetiva quando o graduando se deparar com a construção desse conhecimento e conseguir refletir, analisar e problematizar questões referentes a essa prática. A partir disso, segundo Schön (2000), a visão reflexiva deve fazer parte do currículo tornando-se habitual no processo de formação de professores. Além disso, Pimenta (2010) chama a atenção para outro viés do conceito de "professor-reflexivo", pois afirma que o profissional da educação deve estar acompanhado de políticas públicas efetivas, isto é, deve ter um respaldo para que não isente governantes das responsabilidades e compromissos no que diz respeito aos discursos negativos para com os professores.

A reflexão, também, precisa ser crítica para que se torne significativa na construção deste processo (GHEDIN, 2010). É o que Freire (1996, p. 33) denomina como a ética do fazer histórico, já que enquanto "seres históricosociais, nos tornamos capazes de comparar, de valorar, de intervir, de escolher, de decidir, de romper, por tudo isso nos fizemos seres éticos".

Partindo dessa perspectiva de que o professor-reflexivo seja aquele que tenha a oportunidade de constituir-se como profissional competente, olhando a si mesmo de forma crítica e buscando soluções para possíveis problemas dentro de seu contexto, pensamos ser de grande importância seu estudo e aplicação nos cursos de Licenciatura, uma vez que disciplinas de caráter prático como Estágio Supervisionado ou Prática de Ensino permitem a aplicação deste conceito de forma direta em sua realização. Compartilhamos da ideia de Barreiro e Gebran (2006) que tratam desse processo como
a formação inicial e o estágio devem pautar-se pela investigação da realidade, por uma prática intencional, de modo que as ações sejam marcadas por processos reflexivos entre os professores- formadores e os futuros professores, ao examinarem, questionarem e avaliarem criticamente o seu fazer, o seu pensar e a sua prática. (BARREIRO; GEBRAN, 2006, p. 21).

Sob esta mesma perspectiva, Pimenta e Lima (2010, p.55) tratam do estágio como uma possibilidade de atividades que proporcionam conhecimento, análise, reflexão do trabalho docente, das ações docentes, com a finalidade de entender sua historicidade, identificar seus resultados, os impasses que apresenta e as dificuldades cotidianas. Não apenas pensando na importância da prática docente, pensemos também sobre a relevância da teoria nestas disciplinas. Pois é necessário: 
oferecer aos professores perspectivas de análise para compreender os contextos históricos, sociais, culturais, organizacionais e de si mesmos como profissionais, nos quais se dá sua atividade docente, para neles intervir, transformandoos. (PIMENTA; LIMA, 2010, p. 49).

De acordo com Barreiro e Gebran (2006, p. 118), a relação entre teoria e prática pode definir a qualidade da formação inicial ou continuada do professor, como sujeito autônomo, na construção de sua profissionalização docente. Os autores dialogam com Freire (2017, p. 92) quando este afirma que "todas essas conceituações devem ser lidas com base em uma realidade concreta.". Afinal, o professor-reflexivo parte do conceito, da teoria, para a aplicação prática a fim de que a realidade seja transformada, não pela teoria, mas por meio dela.

Contudo, formar e constituir-se um professor-reflexivo não é uma tarefa fácil nem impossível. Poder ouvir o outro, auxiliar no que for possível e aproximar-se ao máximo da realidade, sem esquecer a relação entre teoria e prática, é provavelmente uma das formas mais eficazes de humanizar o ensino, o profissional, o todo. Afinal, "a sociedade deve ser uma sociedade de diálogo, de participação total, uma sociedade em que cada um tenha uma parcela do poder e a soma das parcelas do poder constitua o poder como tal." (FREIRE, 2017, p. 142). Entendemos poder, no contexto da prática docente, como as ferramentas para a transformação social que a educação permite ao ser humano, ao humanizá-lo e humanizar as relações por meio da geração do conhecimento.

Segundo Saviani (2011), a formação dos professores e a constituição da consciência docente também resultam de aspectos sociais que não podem ser ignorados pelos formadores. Pensar no professorreflexivo requer também uma análise do contexto de educação que temos em nosso país. Embora nosso estudo não objetive analisar de forma pormenorizada esses aspectos, eles não passaram obscurecidos quando da leitura das transcrições dos relatos dos graduandos do curso de Letras da universidade estudada.

\section{A prática de ensino na prática: uma questão de olhar}

Trataremos aqui de algumas informações relevantes sobre a prática de ensino de uma universidade localizada no Sul do Brasil. Consideramos o curso de licenciatura em Letras, especificamente o que habilita para o ensino de português e de espanhol, ou seja, permite ao 
v. 8 (3)

230-249

out-dez

2018

profissional ter dupla habilitação. Além das línguas, a graduação também oferece a habilitação em suas respectivas literaturas. As disciplinas de estágio obrigatório possuem sete encontros presenciais em um semestre, sendo a grande parte deles para que o professor apresente aos alunos a organização e elaboração de suas aulas. O sétimo encontro serve para que todos os estudantes, juntamente com seu professor, ouçam os relatos de experiências de seus colegas e façam as devidas análises e reflexões das práticas vivenciadas.

Ao total são exigidos quatro estágios para este curso. O primeiro corresponde a dez horas somente de observação que poderá ser realizada em qualquer instituição de ensino culminando com a apresentação de um relatório por parte do estudante. Esta prática é feita buscando observar a postura dos professores titulares, dos alunos, setores da instituição, planos de aula, domínio de turma. O segundo estágio exige 10h de observação e $30 h$ de prática no ensino fundamental. O terceiro estágio deve ser realizado no ensino médio e distribuído entre 30h de prática efetiva e 10h de observação. O quarto estágio é de 40h, sendo 10h de observação e $30 h$ de prática devendo ser realizada em espaços de educação não-formais, isto é, instituições que educam, mas não têm a necessidade de certificação do MEC, como, por exemplo, asilos, ONGs, etc. Quanto aos conteúdos que deverão ser desenvolvidos, cada graduando deve elaborar seu plano de aula de acordo com a necessidade do professor titular da escola em que o estudante atuará, ou seja, pode até ser criado um projeto de aula, mas só será aplicado com o aval do professor titular.

Tendo como base este panorama geral da realidade dos estágios docentes exigidos por esta universidade situada na região Sul do país, passamos aos relatos de alguns estudantes envolvidos neste processo. As informações que seguem surgem de um diário de campo utilizado pela professora titular desta disciplina de estágio. São relatos de experiências e conversas entre professor formador e alunoprofessor nos quais nos detemos na esfera do processo de formação de professores-reflexivos e suas experiências.

Com base nos relatos dos alunos-professores, percebemos que essa experiência de dar aula, aqui especificamente da língua espanhola, constitui-se como forma incisiva no que diz respeito à proficiência de língua espanhola, pois conscientiza os alunos-professores sobre as dificuldades linguísticas que ainda os acompanham. Ter a oportunidade de ensinar inserido em um contexto real possibilita a ação de refletir sobre sua própria aprendizagem. A seguir está a transcrição de um dos relatos: 
(1) Foi a primeira vez que dei aula de espanhol. Me senti um pouco inseguro com a língua, mas consegui superar. Me dei conta que o espanhol é mais legal do que imaginava. Os alunos gostam de aprender. E as dificuldades que tive quanto às perguntas, pesquisei e tirei minhas dúvidas. Aprendi tanto quanto os alunos.

É perceptível o processo de reflexão que se inicia neste relato 1, porquanto as experiências vivenciadas tornam o ato de refletir muito mais aguçado, transmitindo ao professor-aluno sentimentos de satisfação ou nem tanto. Mas são esses momentos, em que o alunoprofessor se vê diante da realidade dinâmica da sala de aula, com os alunos e seus questionamentos, que lhe possibilitam a reflexão sobre ser ou estar professor e buscar por ferramentas que contribuam para a melhoria de sua prática. É nesse contexto, que o estudante de Letras contrapõe a teoria à prática. Assim afirma Freire (2017, p. 75-76) que "Uma educação de perguntas é a única educação criativa apta a estimular a capacidade humana de assombramento [...]". Esse assombramento é o que Freire (2017) denomina como antídoto à burocratização do ensino, é a forma com que o professor se mantém encantado com o educar. A constituição do professor-reflexivo passa por esse encantamento, por ver nas dificuldades, nas novas situações, a oportunidade de melhorarse enquanto profissional.

No segundo relato temos o seguinte:

(2) Nunca imaginei que dar aula de espanhol fosse tão legal. A turma gosta muito, mas não sabe nada. Tentava falar em espanhol, mas a maioria não entendia. Foi quando percebi que ou eu sei falar espanhol ou não sei nada mesmo. Vou ter de estudar mais. (risadas)

No relato 2 podemos observar que a necessidade de falar espanhol na turma fez com que o professor-aluno refletisse acerca de sua própria competência oral. Este ato de reflexão o fez perceber que necessitava estudar além do que já sabia para que conseguisse colocar em prática a comunicação da língua espanhola e, assim, alcançar seus objetivos junto aos alunos. Neste momento, acredita que para sua aula ter melhor aproveitamento, deve melhorar sua expressão oral. O aluno que proferiu esse relato atende a um dos saberes para a profissão docente comentada 
V. 8 (3)

$230-249$

out-dez 2018

por Freire (1996), a de que ensinar exige disponibilidade para o diálogo e esse diálogo também diz respeito à própria prática. Como escreveu o autor: "Minha segurança se funda na convicção de que sei algo e de que ignoro algo a que se junta à certeza de que posso saber melhor o que já sei e conhecer o que ainda não sei." (FREIRE, 1996, p. 135).

Desse modo, para que alguém faça essa leitura crítica é necessário ser reflexivo. Essa ação do aluno-professor emissor do relato 2 corrobora a afirmativa de Ghedin (2010, p. 152) de que "Perceber a teoria e a prática como dois lados de um mesmo objeto é imprescindível para se compreender o processo de construção do conhecimento.".

No terceiro relato temos um professor-aluno que diz o seguinte sobre o ensino de gramática da língua espanhola:

(3) Eu achava que não sabia nada de espanhol. Quando cheguei para dar aula para o ensino médio vi que sei muito e eles que não sabem nada. Sei usar os artigos e alguns verbos corretamente. Me senti muito bem, me senti a professora.

Neste relato (3) é visível a autoestima do professor-aluno. Segundo seu relato, percebeu somente depois de dar aula que tinha certo conhecimento na língua espanhola, conhecimento suficiente para atender a turma em que estava desenvolvendo seu trabalho. Este relato nos remete a uma questão muitas vezes esquecida que trata do sentimento de insegurança por parte dos alunos da licenciatura. Ter a oportunidade de dar aula, vivenciar as experiências verdadeiras com turmas reais, vai além de um cumprimento de horas exigidas para conseguir o diploma. Se o aluno-professor consegue fazer uma reflexão crítica acerca de suas aulas e de seu conhecimento específico da língua, isso faz com que ele busque sua afirmação como professor e encontre sua identidade docente.

No caso analisado, do relato 3, há a demonstração clara de autorrealização com a profissão escolhida. Essa atitude, embora movida por questões subjetivas, contribuiu para a manutenção desse profissional atuando na escola. É essa subjetividade que Scoz (2012) retoma quanto à produção de sentido docente quando afirma que se deve considerar

o professor como sujeito do conhecimento, portador de crenças, valores e expectativas, enfim, alguém que, em seus processos subjetivos, vai produzindo sentidos em relação aos processos de aprender e ensinar. (SCOZ, 2012, p. 16). 
Portanto, o exercício de pensar ou repensar as práticas docentes, faz com que o aluno-professor se torne protagonista em um processo de aprendizagem e encontre uma nova identidade profissional: o ser professor. Essa formação vai além do mero aporte teórico a que estamos acostumados a vivenciar nos bancos das universidades. Essa formação a que nos reportamos nesse estudo, corroborada tanto na fala dos alunos-professores ouvidos quanto nos autores que dialogam conosco, parte de uma base humanista, subjetiva do sujeito.

Sobre esse aspecto da formação do professor-reflexivo como sujeito subjetivo, podemos dialogar com Scoz (2012). A autora afirma que

A subjetividade e a identidade podem ser compreendidas como algo em construção, com base nos sentidos que os sujeitos vão produzindo na condição singular em que se encontram inseridos em suas trajetórias de vida e, ao mesmo tempo, em suas diferentes atividades e formas de relação. (SCOZ, 2012, p. 28-29).

Retomando o quehavíamos mencionado a respeito do perfil dos alunos das licenciaturas das instituições privadas, como é o caso dos estudantes do curso de Letras da Universidade objeto deste estudo, é possível depreender que suas expectativas quanto à profissão docente decorram de suas experiências também como alunos que foram na educação básica. Também segundo Imbernón (2009), a formação inicial do professor, nos primeiros anos da graduação, é crucial para a elaboração mental de sua própria identidade, inserida em um contexto, muitas vezes, de descrédito diante da profissão. Segundo o autor,

É uma etapa muito importante, já que o conjunto de atitudes, valores e funções que os alunos de formação inicial conferem à profissão será submetido a uma série de mudanças e transformações em consonância com o processo socializador que ocorre nessa formação. É ali que se geram determinados hábitos que incidirão no exercício da profissão (IMBERNÓN, 2009, p.55).

Assim temos claramente, o que também pode ser retomado dos relatos dos alunos-professores, o quanto a subjetividade está intrinsicamente atrelada à formação da identidade do professor. Ao entrarem no curso, esses estudantes têm uma série de expectativas quanto a sua futura atuação docente e é no estágio obrigatório, exigido por lei para a conclusão do curso, que esses sujeitos se deparam com a realidade da escola. Saviani (2011) é taxativo em afirmar que uma maneira de diminuir a falta de professores na educação básica seria aproximar a universidade das escolas, enquanto formadora, tendo em vista a realidade de atuação dos alunos-professores. Isso posto não somente no período dos estágios, mas em permanente parceria. 
v. 8 (3)

230-249

out-dez

2018

No caso específico dos alunos do curso de Letras, habilitandose como professores de língua espanhola, os relatos demonstram que na prática os alunos-professores puderam se dar conta das lacunas ainda existentes quanto à aquisição da língua por eles próprios. Foi essa observação que levou dois deles a perceberem o quanto precisam estudar e a se aprimorar e no relato de um dos alunos, a aula centrada na gramática pareceu mais confortável, em dissonância com o uso da língua como ferramenta comunicativa. Desse modo, foi possível observar e categorizar os alunos como os que, refletindo sobre sua prática, creem que precisam melhorá-la e aqueles que, por observarem que atuam bem na posição docente, aumentam sua autoestima e valorização profissional, o que pode gerar a busca por se tornarem melhor profissionais.

Outrossim, observar que esses estudantes têm sonhos ao adentrarem as portas da universidade e que esses sonhos precisam continuar vivos em sua prática docente, é imprescindível para a formação não só inicial, mas também contínua desses profissionais. Porque é na luta pela realização dos sonhos que outros sonhos são criados e recriados e a educação se mantém viva como prática para liberdade, para emancipação dos sujeitos. (FREIRE, 2017).

Dessa forma, voltamos ao conceito de educação humana que emerge da ideia do ser social e historicizado, defendida por Freire (2015) e Pimenta (2010). É na prática da reflexão que o professor-reflexivo se constitui como ser humano autônomo, gerenciador de sua aprendizagem. Tanto a universidade quanto o espaço da escola precisam proporcionar momentos e instrumental teórico para que o aluno-professor mantenha a continuidade de sua formação por meio da reflexão.

Essa prática de garantir os espaços de reflexão pretende contribuir para a formação do senso de responsabilidade, dos princípios de solidariedade e de cidadania, em cada sujeito, seja de que idade for e em que posição social estiver. (CAMPOS, 2009).

Como afirma Campos (2009), a reflexão gera sentimentos e senso de comprometimentonos sujeitos quantoàs suasresponsabilidades. Essa atribuição da reflexão, para Freire (2015), configura a consciência do ser humano que faz dele um ser humanizado. É o que o autor afirma, também, quando se reporta ao que seja o pensar certo na ação docente: "Pensar certo demanda profundidade e não superficialidade na compreensão e na interpretação dos fatos." (FREIRE, 1996, p. 33). Dessa feita, espera-se dos alunos-professores uma postura de professor- 
reflexivo, formada desde o início de sua entrada na licenciatura. Formação inicial e contínua por todo seu fazer docente, porquanto "os sujeitos críticos que exercitam e confrontam seus pensamentos podem gerar novos sentidos, que contribuem para modificações neles mesmos e nos espaços sociais onde atuam." (SCOZ, 2012, p. 34-35). É nessa atuação e na modificação de suas práticas, que esses estudantes de licenciatura se constituem professores protagonistas de sua prática docente em uma sociedade em constante mudança e transitoriedade.

\section{Considerações finais}

A investigação aqui apresentada buscou analisar a formação dos professores nos cursos de licenciatura em Letras pela perspectiva do professor-reflexivo e do humanismo freiriano, o que nos levou a entrecruzar os dados coletados dos relatos de alunos do curso de Letras em questão com autores como Pimenta (2010) e Freire (1996, 2015 e 2017). Pela análise dos dados que seguiu a técnica de Bardin (2016), duas categorias puderam ser observadas: a dos alunos que, na prática do estágio obrigatório, se viram diante de lacunas quanto à sua formação e, após reflexão sobre suas atuações, perceberam que precisam estudar e se aperfeiçoar mais; e a dos alunos que, diante de uma classe real de alunos, também ao cursarem o estágio obrigatório, atuaram de maneira satisfatória, o que aumentou sua autoestima enquanto futuros profissionais.

Nos dois casos, a consciência da necessidade da reflexão esteve presente. São alunos que tiveram contato com teorias e que na prática puderam perceber, por meio do processo autorreflexivo, as distâncias que precisam ser encurtadas entre teoria e prática para que se tornem efetivamente profissionais de êxito.

Como observamos no diálogo com os autores e os relatos dos alunos-professores, o processo reflexivo faz parte da constituição do sujeito enquanto ser humano e, portanto, é permeado de subjetividade. A própria ideia que esses alunos têm da profissão que escolheram, suas demandas e histórias, reflete em sua formação e atuação como docentes e não pode ser ignorada. Atuar de maneira a considerar os perfis dos alunos do curso de licenciatura em Letras, aqui dos que buscam a habilitação para o ensino da língua espanhola, é crucial para que a universidade cumpra seu papel como formadora de profissionais que atuem com qualidade dentro das escolas. 
v. 8 (3)

$230-249$

out-dez

2018

Em um Brasil em que a educação continua sucateada e que a língua espanhola passou a ser secundária na educação básica, podendo ser dispensada pelos sistemas educativos, sejam municipais e/ou estaduais, alunos demonstrarem tal grau de satisfação com sua atuação docente é um ganho para as comunidades educativas em que irão atuar.

Portanto, é mister observar a necessidade de todos os estudantes de desenvolverem a consciência do professor-reflexivo desde o início da graduação, estendendo-se por toda a trajetória docente destes profissionais, calcados em uma visão humanista e integral da pessoa humana, porquanto somos feitos de subjetividades e cada um de nós imprime à nossa carreira profissional nossas expectativas e desilusões frente às não respondidas. Quando o profissional da educação atua com consciência de seu papel como transformador da sociedade, ele reflete sua prática cotidianamente em busca de melhorias e autovalorização, o que refletirá em satisfação pessoal, mesmo diante de tempos e dos espaços obscuros pelos quais passa a educação em nosso país.

\section{Referências}

BARDIN, Laurence. Análise de Conteúdo. Lisboa: Edições 70, 2016.

BARREIRO, I. M. de F.; GEBRAN, R. A. Prática de ensino e estágio supervisionado na formação de professores. São Paulo: Avercamp, 2006.

BRASIL/MEC/INEP. Censo da Educação Superior: notas estatísticas. Brasília, 2016. Disponível em: http://download.inep.gov.br/educacao_superior/ censo_superior/documentos/2016/notas_sobre_o_censo_da_educacao_ superior_2016.pdf. Acesso em: 28 mai. 2018.

BRASIL. Base Nacional Comum Curricular. Homologada em 20 de Dezembro de 2017. Disponível em: <http://portal.mec.gov.br/index.php?option=com docman\&view=download\&alias $=79601$-anexo - texto-bncc - reexportado-pdf2\&category_slug=dezembro-2017-pdf\&Itemid=30192>. Acesso em: 20 mai. 2018.

CAMPOS, Regina Célia. A formação humana: reflexões sobre educação e trabalho. In: COELHO, Maria Inês de Matos. COSTA, Anna Edith Bellico da (Orgs.). A educação e a formação humana: tensões e desafios na contemporaneidade. Porto Alegre: Artmed, 2009.

FREIRE, Paulo. Pedagogia da autonomia. 29a ed. São Paulo: Paz e Terra, 1996. Pedagogia do oprimido. 59 a ed. Rio de Janeiro: Paz e Terra, 2015. Paz e Terra, 2017.

Por uma pedagogia da pergunta. $8^{\mathrm{a}}$ ed. São Paulo/Rio de Janeiro: GHEDIN, E. Professor reflexivo: da alienação da técnica à autonomia da crítica. 
In: PIMENTA, S. G.; GHEDIN, E. (Org.). Professor reflexivo no Brasil: gênese e crítica de um conceito. São Paulo: Cortez, 2010. p. 148-173.

IMBERNÓN, Francisco. Formação docente e profissional: formar-se para a mudança e a incerteza. $7^{\mathrm{a}}$ ed. São Paulo: Cortez, 2009.

PIMENTA, S. G. Professor reflexivo: construindo uma crítica. In: PIMENTA, S. G.; GHEDIN, E. (Org.). Professor reflexivo no Brasil: gênese e crítica de um conceito. São Paulo: Cortez, 2012. p. 17-52.

PIMENTA, S. G.; LIMA, M. S. L. Estágio e docência. 5. ed. São Paulo: Cortez, 2010.

SAVIANI, Dermeval. Formação de professores: aspectos históricos e teóricos do problema no contexto brasileiro. Revista Brasileira de Educação. v. 14, n. 40 jan./abr. 2009. p. 143-155.

Formação de professores no Brasil: dilemas e perspectivas. Poíesis Pedagógica. v. 9, n. 1. jan./jun. 2011. p. 07-19.

SCHÖN, Donald. Formar professores como profissionais reflexivos. In: NÓVOA, A. (Org.). Os professores e sua formação. Lisboa: Dom Quixote, 1995. p. 7791.

Educando o profissional reflexivo: um novo design para o ensino e aprendizagem. Porto Alegre: Artes Médicas Sul, 2000.

SCOZ, Beatriz. Identidade e subjetividade de professores: sentidos do aprender e do ensinar. $2^{\mathrm{a}}$ ed. Petrópolis/RJ: Vozes, 2012.

WEBER, Max. A "objetividade" do conhecimento nas ciências sociais. In: COHN, G. (Org.). WEBER, M. Sociologia. São Paulo: Ática, 2004. p. 79-127. 